\title{
Synthesis of nucleotide-activated disaccharides with $\beta$-galactosidase from Bacillus circulans and $\alpha$-galactosidase from Bifidobacterium adolescentis
}

\author{
Veronika Nieder ${ }^{\mathrm{a}}$, Stefan P. Marx ${ }^{\mathrm{a}}$, Ricardo Gutiérrez Gallego ${ }^{\mathrm{b}}$, \\ Johannis P. Kamerling ${ }^{\mathrm{b}}$, Johannes F.G. Vliegenthart ${ }^{\mathrm{b}}$, Lothar Elling ${ }^{\mathrm{a}, *}$ \\ ${ }^{a}$ Department of Biotechnology/Biomaterial Sciences, Helmholtz Institute of Biomedical Engineering, \\ Worringer Weg 1, D-52056, RWTH Aachen, Germany \\ ${ }^{\mathrm{b}}$ Section of Glycoscience and Biocatalysis, Department of Bio-Organic Chemistry, Bijvoet Center, \\ Utrecht University, Utrecht, The Netherlands
}

Received 6 June 2002; accepted 19 July 2002

\begin{abstract}
The enzymatic synthesis of nucleotide-activated disaccharides by glycosidase-catalyzed transglycosylation reactions was investigated. High product yields were obtained when the kinetically driven syntheses were performed in frozen aqueous solutions at $-5^{\circ} \mathrm{C}$. $\beta$-Galactosidase from Bacillus circulans catalyzed the transfer of D-galactose from lactose onto the nucleotide sugar UDP-Gal stereo- and regioselectively, forming the nucleotide disaccharide $\operatorname{Gal}(\beta 1-4) \mathrm{Gal}(\alpha 1$-UDP. $\alpha$-Galactosidase from Bifidobacterium adolescentis accepted UDP-Gal and UDP-Glc only when the reaction was performed at $-5^{\circ} \mathrm{C}$ with melibiose as glycoside donor. Enzyme and donor concentrations were optimized for the preparative synthesis yielding $\operatorname{Gal}(\alpha 1-3) \mathrm{Glc}(\alpha 1-\mathrm{UDP}$ and $\mathrm{Gal}(\alpha 1-3) \mathrm{Gal}(\alpha 1-\mathrm{UDP}$ as analyzed by MALDI-TOF mass spectrometry and 1D and 2D ${ }^{1} \mathrm{H}$ and ${ }^{13} \mathrm{C}$ NMR spectroscopy. The reported products are invaluable tools for studies on their possible biochemical function as donor substrates or inhibitors of Leloir glycosyltransferases.

() 2002 Elsevier Science B.V. All rights reserved.
\end{abstract}

Keywords: Glycosidase; Transglycosylation; Nucleotide sugars; Nucleotide-activated disaccharides; Enzymatic synthesis

\section{Introduction}

Nucleotide-activated oligosaccharides are glycoconjugates, which were first isolated from milk of mammals, including man [1-3], pig [4], goat [5,6], and sheep [7]. They were also found in the hen oviduct $[8,9]$. The structural characterization revealed that most of these structures are based on UDP- $N$-acetyl-

\footnotetext{
* Corresponding author. Tel.: +49-241-80-26470; fax: +49-241-80-22387.

E-mail address: 1.elling@biotec.rwth-aachen.de (L. Elling).
}

$\alpha$-D-glucosamine (UDP-GlcNAc) with Gal( $\beta 1-4)$ Glc$\mathrm{NAc}(\alpha 1-\mathrm{UDP}$ (UDP-LacNAc) as the main component. The different structures encountered thus far have been summarized by Zervosen et al. [10]. Although, these glycoconjugates are known to be present in higher animals, their biosynthesis and biological function have not yet been elucidated.

In contrast, it has been proven that the biosynthesis of different cell-wall carbohydrate polymers in archaebacteria proceeds via nucleotide-activated oligosaccharides. GalNAc( $\beta 1-3)$ GlcNAc-UDP was identified as an intermediate in the biosynthesis of 
pseudomurein [11]. The nucleotide oligosaccharides GlcA(1-3)GalNAc-UDP and GlcA(1-3)GalNAc(1-4) GalNAc-UDP were isolated as structural elements in the biosynthesis of methanochondroitin [12]. Nucleotide oligosaccharides on the basis of UDP-GlcNAc, UDP-Gal, GDP-ManNAc, and UDP-ManNAc were found as precursors in the biosynthesis of the S-layerglycoproteins [13]. However, the enzymes involved in these biosynthetic routes have not been identified yet.

In the last decade the synthesis of natural and modified carbohydrate structures, involving both chemical and enzymatic steps, has gained a high standard [14]. However, access to nucleotide oligosaccharides has not been described so widely, which may be due to difficulties in the availability of nucleotide monosaccharides as starting material.
In the course of our work we have developed efficient enzymatic routes for the production of nucleotide sugars [15]. In the context of nucleotide-activated oligosaccharides our goal is to provide a set of different nucleotide di- and trisaccharides by enzymatic methods in order to facilitate studies on their biosynthesis and biological functions. Moreover, in synthetic applications these compounds may be found to serve as building-block donor substrates of Leloir glycosyltransferases, thus providing engineered glycoconjugates in a convergent enzymatic synthesis approach.

We suggested that Leloir glycosyltransferases may be responsible for the synthesis of milk nucleotide oligosaccharides in vivo by using nucleotide sugars as acceptor substrates [16]. Although the $\beta 1,4$-galactosyltransferase ( $\beta 4 \mathrm{GalT1}$, EC 2.4.1.38) was considered

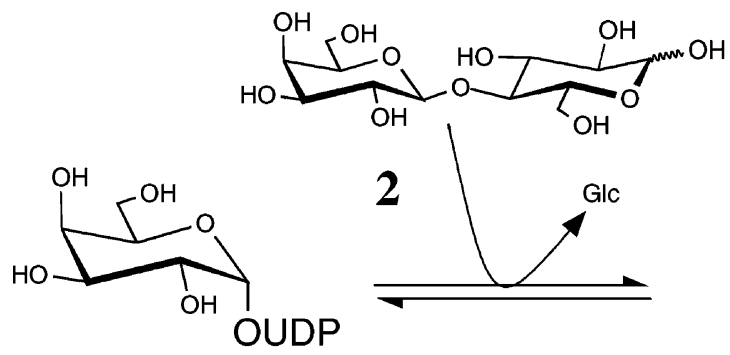

1
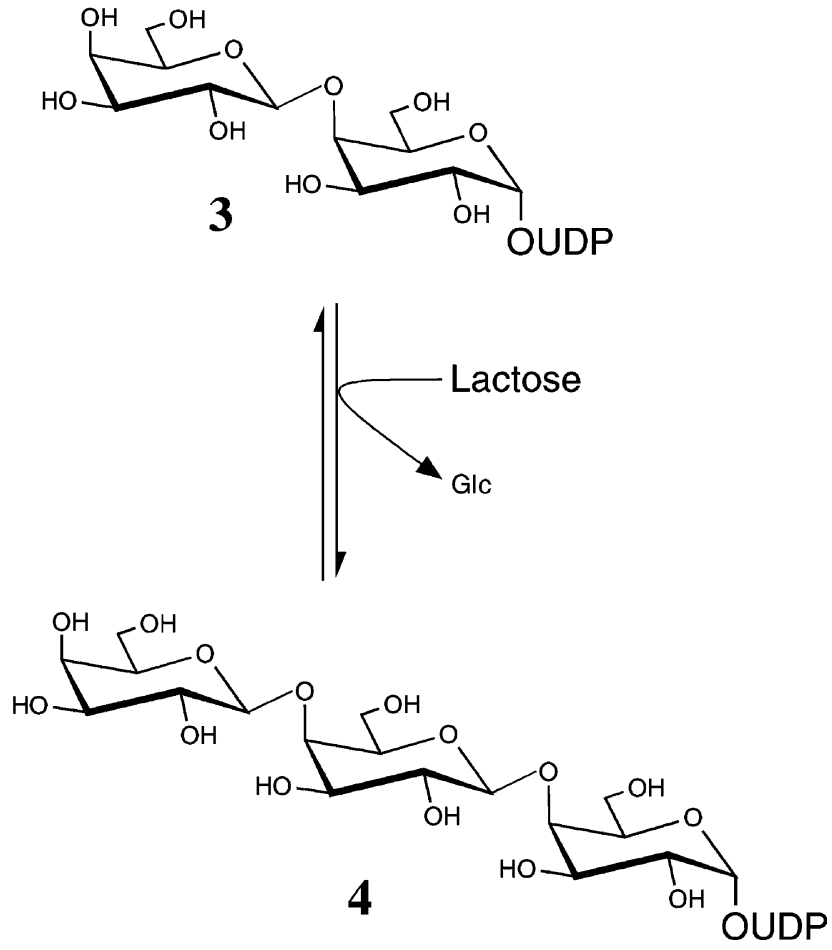

Fig. 1. Synthesis of $\operatorname{Gal}(\beta 1-4) \mathrm{Gal}(\alpha 1-\mathrm{UDP}(\mathbf{3})$ and $\mathrm{Gal}(\beta 1-4) \mathrm{Gal}(\beta 1-4) \mathrm{Gal}(\alpha 1-\mathrm{UDP}$ (4) by $\beta$-galactosidase from Bacillus circulans at $-5{ }^{\circ} \mathrm{C}$ with lactose (2) as donor and UDP-Gal (1) as acceptor substrate. 

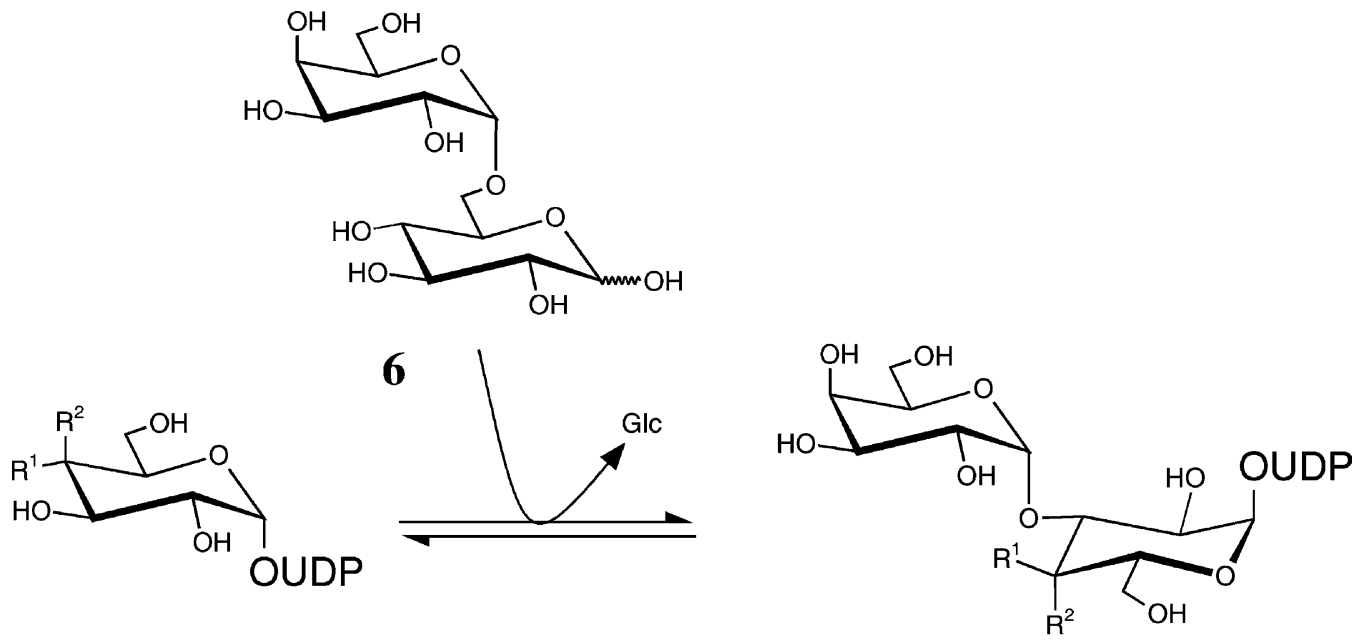

$$
\begin{aligned}
& 5 \mathrm{R}^{1}=\mathrm{OH}, \mathrm{R}^{2}=\mathrm{H} \\
& \mathbf{1}^{1}=\mathrm{H}, \mathrm{R}^{2}=\mathrm{OH}
\end{aligned}
$$

$$
\begin{aligned}
7 \mathbf{a} \mathrm{R}^{1} & =\mathrm{OH}, \mathrm{R}^{2}=\mathrm{H} \\
\mathbf{7 b} \mathrm{R}^{1} & =\mathrm{H}, \mathrm{R}^{2}=\mathrm{OH}
\end{aligned}
$$

Fig. 2. Synthesis of $\operatorname{Gal}(\alpha 1-3) \operatorname{Glc}(\alpha 1-\mathrm{UDP}$ (7a) and $\mathrm{Gal}(\alpha 1-3) \mathrm{Gal}(\alpha 1-\mathrm{UDP}$ (7b), respectively, by $\alpha$-galactosidase from Bifidobacterium adolescentis at $-5^{\circ} \mathrm{C}$ with melibiose (6) as donor and UDP-Glc (5) or UDP-Gal (1), respectively, as acceptor substrates.

to accept only $N$-acetyl- $\beta$-D-glucosaminides as substrates [17], we demonstrated that UDP- $\alpha$-D-GlcNAc is recognized in vitro as acceptor substrate of $34 \mathrm{GalT} 1$ from human and bovine milk synthesizing UDP-LacNAc [16].

On the other hand glycosidases offer a more flexible strategy to synthesize nucleotide di- and oligosaccharides. However, a first study by Jourdian and Distler [6] using $\beta$-galactosidase from bovine testes revealed the synthesis of the regioisomers $\operatorname{Gal}(\beta 1-$ $3,4,6) \mathrm{GlcNAc}(\alpha 1$-UDP rather than one regioisomer. In contrast, we recently reported on the stereo- and regioselective synthesis of nucleotide-activated diand trisaccharides by $\beta$-galactosidase from Bacillus circulans with UDP-GlcNAc and UDP-Glc as acceptor substrates [10]. We demonstrated that an efficient synthesis with relatively high product yields was accomplished in frozen solution at $-5^{\circ} \mathrm{C}$. The products UDP-LacNAc, Gal( $\beta 1-4) \mathrm{Glc}(\alpha 1-\mathrm{UDP}$ (UDPlactose), and the corresponding UDP-trisaccharides $\operatorname{Gal}(\beta 1-4) \mathrm{Gal}(\beta 1-4) \mathrm{GlcNAc-UDP}$ and $\mathrm{Gal}(\beta 1-4)$ Gal $(\beta 1-4)$ Glc-UDP were obtained.

The improved product yields in frozen aqueous solution are most likely due to a reduced hydrolysis of the products and high concentrations of substrates in the small remaining liquid phase [18]. We concluded from these studies that further substrates and glycosidases may be exploited for the synthesis in frozen aqueous solutions [10].

In the present study, we present results on the utilization of $\operatorname{UDP}(\alpha 1-\mathrm{Gal}$ (1) as substrate of $\beta$-galactosidase from $B$. circulans (Fig. 1) and the synthetic application of $\alpha$-galactosidase from Bifidobacterium adolescentis (Fig. 2$)$ using $\operatorname{UDP}(\alpha 1-\mathrm{Gal}$ (1) and $\operatorname{UDP}(\alpha 1-$ Glc (5) as substrates.

\section{Experimental}

\subsection{Materials}

$\beta$-Galactosidase from $B$. circulans was purchased from Daiwa Kasei KK (Biolacta N5 ${ }^{\mathrm{TM}}$, Osaka, Japan). $\alpha$-Galactosidase from $B$. adolescentis was produced and purified as described previously [19]. Lactose, melibiose, $\operatorname{Gal}(\alpha 1-p N P$ and UDP-Glc were obtained from Sigma (Deisenhofen, Germany). UDP-Gal was synthesized as described elsewhere [20]. Sodium citrate, sodium acetate, sodium phosphate and acetic acid were from Roth (Karlsruhe, Germany). 


\section{2. $\beta$-Galactosidase from Bacillus circulans:} preparative synthesis of $\operatorname{Gal}(\beta 1-4) \mathrm{Gal}(\alpha 1$ $U D P(\mathbf{3})$

For the preparative synthesis of $\mathbf{3}$ using $\mathbf{1}$ as acceptor and lactose (2) as donor substrate, optimized reaction conditions were used [10]. For the transglycosylation reaction $500 \mathrm{mM}$ of $2(0.60 \mathrm{mmol}$, $205 \mathrm{mg}), 100 \mathrm{mM}$ of $1(0.12 \mathrm{mmol}, 71 \mathrm{mg}$, disodium salt) and $10 \mathrm{U} / \mathrm{ml} \beta$-galactosidase $(12 \mathrm{U})$ were dissolved in $20 \mathrm{mM}$ sodium acetate/acetic acid $(1.2 \mathrm{ml})$, $\mathrm{pH}$ 4.5. Prior to incubation at $-5^{\circ} \mathrm{C}$ the solution was divided into aliquots of $120 \mu \mathrm{l}$, which were immediately frozen in liquid $\mathrm{N}_{2}$. The reaction was terminated after 2 days by heating at $95^{\circ} \mathrm{C}$ for $5 \mathrm{~min}$. The aliquots of each reaction were pooled and analyzed by HPLC. The isolation of $\mathbf{3}$ was performed as described previously [10].

\section{3. $\alpha$-Galactosidase from Bifidobacterium adolescentis: Gal $(\alpha 1-3)$ Glc( $\alpha 1-U D P$ (7a)}

\subsubsection{Influence of temperature and donor substrate on the reaction yield}

The effect of temperature and donor substrate was investigated with UDP-Glc (5) as acceptor. Melibiose (6) and $\operatorname{Gal}(\alpha 1-p \mathrm{NP}$ were tested as donor substrates at 30 and $-5^{\circ} \mathrm{C}$. The reaction mixtures contained $100 \mathrm{mM}$ of $5(10 \mu \mathrm{mol}, 6.1 \mathrm{mg}$, disodium salt), $190 \mathrm{mM}$ of $\mathrm{Gal}(\alpha 1-p \mathrm{NP}(19 \mu \mathrm{mol}, 5.7 \mathrm{mg})$ or $500 \mathrm{mM}$ of $6(50 \mu \mathrm{mol}, 17.1 \mathrm{mg})$, respectively, and $0.7 \mathrm{U} / \mathrm{ml} \alpha$-galactosidase $(70 \mathrm{mU})$ in a final volume of $100 \mu 150 \mathrm{mM}$ citrate/phosphate buffer, $\mathrm{pH}$ 6.0. For incubation at $-5^{\circ} \mathrm{C}$ the reaction mixtures were divided into aliquots of $10 \mu$ l, which were immediately frozen in liquid $\mathrm{N}_{2}$. Following the incubation (see Section 3) the samples were heated at $95^{\circ} \mathrm{C}$ for $5 \mathrm{~min}$ prior to HPLC. Analysis of samples were performed over a reaction period of $140 \mathrm{~min}$ at $30^{\circ} \mathrm{C}$ or 7 days at $-5^{\circ} \mathrm{C}$.

The concentration of the donor substrate 6 was varied between $100 \mathrm{mM}(10 \mu \mathrm{mol}, 3.4 \mathrm{mg})$ and $500 \mathrm{mM}$ $(50 \mu \mathrm{mol}, 17.1 \mathrm{mg})$ with $100 \mathrm{mM}$ of $5(10 \mu \mathrm{mol}$, $6.1 \mathrm{mg}$, disodium salt) and $0.5 \mathrm{U} / \mathrm{ml} \alpha$-galactosidase $(50 \mathrm{mU})$ in the assay at $-5^{\circ} \mathrm{C}$ as described above. The enzyme reactions were terminated at the indicated incubation periods (see Section 3) and the samples were analyzed by HPLC.

\subsubsection{Influence of enzyme concentration on the reaction yield}

The effects of two concentrations of $\alpha$-galactosidase were tested for the transglycosylation reaction at $-5^{\circ} \mathrm{C}$. The reaction mixtures contained $300 \mathrm{mM}$ of 6 (45 $\mu \mathrm{mol}, 15.4 \mathrm{mg}), 100 \mathrm{mM}$ of 5 (15 $\mu \mathrm{mol}, 9.2 \mathrm{mg})$ and 0.5 or $6 \mathrm{U} / \mathrm{ml}(75$ or $900 \mathrm{mU}) \alpha$-galactosidase dissolved in $150 \mu 150 \mathrm{mM}$ citrate/phosphate buffer, pH 6.0.

The reaction mixtures were divided into aliquots of $15 \mu \mathrm{l}$, immediately frozen in liquid $\mathrm{N}_{2}$ and incubated for 20 days at $-5^{\circ} \mathrm{C}$. The samples were analyzed by HPLC.

\subsubsection{Preparative synthesis of Gal $(\alpha 1-3)$ \\ Glc( $\alpha 1-U D P(7 \mathbf{a})$ and Gal $(\alpha 1-3) G a l(\alpha 1-U D P(7 \mathbf{b})$}

For the synthesis of $7 \mathbf{a} 100 \mathrm{mM}$ of $6(200 \mu \mathrm{mol}$, $68.5 \mathrm{mg}), 100 \mathrm{mM}$ of $5(200 \mu \mathrm{mol}, 122.0 \mathrm{mg}$, disodium salt) and $0.5 \mathrm{U} / \mathrm{ml} \alpha$-galactosidase (1 U) were dissolved in $50 \mathrm{mM}$ sodium citrate/phosphate buffer, pH $6.0(2 \mathrm{ml})$. The synthesis of $7 \mathbf{b}$ was performed dissolving $100 \mathrm{mM}$ of $6(140 \mu \mathrm{mol}, 48 \mathrm{mg})$, $100 \mathrm{mM}$ of 1 (163 $\mu \mathrm{mol}, 100 \mathrm{mg}$, disodium salt) and $0.3 \mathrm{U} / \mathrm{ml} \alpha$-galactosidase $(0.4 \mathrm{U})$ in $50 \mathrm{mM}$ sodium citrate/phosphate buffer, $\mathrm{pH} 6.0(1.4 \mathrm{ml})$. Prior to incubation at $-5{ }^{\circ} \mathrm{C}$ the reaction mixtures were divided into aliquots of $100 \mu \mathrm{l}$, which were immediately frozen in liquid $\mathrm{N}_{2}$. The reaction was stopped after 21 days by heating at $95^{\circ} \mathrm{C}$ for $5 \mathrm{~min}$. The pooled samples were then analyzed by HPLC and product isolation was conducted as described previously [10].

\subsection{Analytical methods}

\subsubsection{HPLC analysis}

Samples were analyzed by normal-phase HPLC on a Glycosep ${ }^{\mathrm{TM}} \mathrm{N}$-column $(4.6 \mathrm{~mm} \times 250 \mathrm{~mm}$; Oxford GlycoSciences, Oxford, England). The conditions for the gradient elution were applied according to Guile et al. [21]. Solvent A consisted of $50 \mathrm{mM}$ ammonium formate, $\mathrm{pH} 4.4$, and solvent $\mathrm{B}$ was acetonitrile. Initial conditions for the gradient were $35 \% \mathrm{~A}$ at a flow rate of $0.4 \mathrm{ml} / \mathrm{min}$, followed by a linear gradient of $35-53 \%$ A over $72 \mathrm{~min}$, and finally $53-100 \%$ A over the next $3 \mathrm{~min}$. The flow rate was then increased to $1 \mathrm{ml} / \mathrm{min}$ over the next $2 \mathrm{~min}$, and the column was washed with $100 \%$ A before equilibration with $35 \%$ A. Nucleotide sugars could be detected at $256 \mathrm{~nm}$. 


\subsubsection{Mass spectrometry and NMR spectroscopy}

The analysis of the isolated products by negative-ion mode MALDI-TOF mass spectrometry and 1D/2D ${ }^{1} \mathrm{H}$ - and ${ }^{13} \mathrm{C}-\mathrm{NMR}$ experiments was conducted as previously described [10].

\section{Results and discussion}

\section{1. $\beta$-Galactosidase from Bacillus circulans: preparative synthesis and characterization of Gal $(\beta 1-4) G a l(\alpha 1-U D P(3)$}

Previously, we have demonstrated that $\beta$-galactosidase from $B$. circulans accepts also UDP-Gal besides UDP-Glc and UDP-GlcNAc resulting in the formation of the corresponding Gal( $\beta 1-4)$ elongated UDP-diand trisaccharides [10]. In order to facilitate studies of nucleotide disaccharides as donor substrates or inhibitors of different galactosyltransferases we here present the preparative synthesis of $\mathbf{3}$ as a further UDP-disaccharide.

The transglycosylation reaction of $\beta$-galactosidase at $-5{ }^{\circ} \mathrm{C}$ yielded $25 \%$ of $\mathbf{3}$ and $4.3 \%$ of a product which is suggested to be the corresponding activated trisaccharide $\operatorname{Gal}(\beta 1-4) \operatorname{Gal}(\beta 1-4) \operatorname{Gal}(\alpha 1-U D P \quad$ (4) according to HPLC analysis (Fig. 1). The formation of the glycosidic linkages in $\mathbf{3}$ and $\mathbf{4}$ was expected to be analogous to the UDP-di- and trisaccharides previously obtained [10]. The overall yield after isolation was $6.7 \%(8.7 \mu \mathrm{mol}, 6.7 \mathrm{mg})$ for 3 with a purity of $100 \%$ according to HPLC. The suggested UDP-trisaccharide 4 was not further isolated and characterized.

For 3 with negative-ion mode MALDI-TOF mass spectrometry a pseudomolecular ion peak was observed at $m / z, 729\left([M-\mathrm{H}]^{-}, \mathrm{Hex}_{2}\right.$-UDP $)$. The appearance of the free acid, rather than the sodiated form was also observed for the other products [10] and is due to the extensive salt precipitation during isolation of the product.

The $1 \mathrm{D}{ }^{1} \mathrm{H}$ NMR spectrum of $\mathbf{3}$ (Fig. 3A) showed four signals downfield of the HOD signal $(\delta$ 4.751). Two of these signals at $\delta 7.951\left({ }^{3} J_{5,6} 8.4 \mathrm{~Hz}\right)$ and $\delta$ $5.975\left({ }^{3} J_{5,6} 8.4 \mathrm{~Hz}\right)$ were attributed to the uracil-ring protons U6 and U5, respectively, based on literature $[22,23]$. The anomeric signal at $\delta 5.986$ was assigned to $\mathrm{H}-1$ of the ribose residue $\mathrm{R}$ ( $\beta$ configuration, furanose ring form), whereas the remaining anomeric signal at $\delta 5.363$ was assigned to $\mathrm{H}-1$ of the Gal residue $\mathrm{A}$ (a configuration, pyranose ring form) linked to the phosphate group. The anomeric doublet at $\delta$ 4.600 , upfield of the HOD resonance, is derived from $\mathrm{H}-1$ of the Gal residue $\mathrm{B}$ ( $\beta$ configuration, pyranose ring form). By means of 2D TOCSY, ROESY and HMBC experiments all resonances observed in the 1D ${ }^{1} \mathrm{H}$ and ${ }^{13} \mathrm{C}$ spectra could be assigned (Table 1). In the TOCSY spectrum (data not shown) the three identified anomeric ${ }^{1} \mathrm{H}$ signals were used to as-

Table 1

${ }^{1} \mathrm{H}$ and ${ }^{13} \mathrm{C}$ chemical shifts of $\mathrm{Gal}(\beta 1-4) \mathrm{Gal}(\alpha 1$-UDP $(3)$ prepared with $\beta$-galactosidase from Bacillus circulans and Gal $(\alpha 1-3)$ Glc( $\alpha 1$-UDP (7a) prepared with $\alpha$-galactosidase from Bifidobacterium adolescentis recorded in $\mathrm{D}_{2} \mathrm{O}$ at $300 \mathrm{~K}$

\begin{tabular}{|c|c|c|c|c|}
\hline \multirow[t]{2}{*}{ Atom $^{a}$} & \multicolumn{2}{|l|}{${ }^{1} \mathrm{H}^{\mathrm{b}}$} & \multicolumn{2}{|l|}{${ }^{13} C^{b}$} \\
\hline & 3 & $7 a$ & 3 & $7 a$ \\
\hline A1 & 5.636 & 5.606 & - & 94.56 \\
\hline A2 & 3.892 & 3.548 & - & 71.69 \\
\hline A3 & 4.011 & 3.776 & 70.42 & 73.73 \\
\hline A4 & 4.262 & 4.074 & 78.74 & - \\
\hline A5 & 3.813 & 4.019 & - & 72.43 \\
\hline $\mathrm{A} 6 \mathrm{a}^{\mathrm{c}}$ & - & 3.763 & - & 61.07 \\
\hline $\mathrm{A} 6 \mathrm{~b}^{\mathrm{c}}$ & - & - & - & - \\
\hline B1 & 4.600 & 4.985 & 105.22 & 98.29 \\
\hline B2 & 3.580 & 3.799 & 72.09 & 69.47 \\
\hline B3 & 3.659 & 3.896 & 73.45 & 70.96 \\
\hline B4 & 3.905 & 4.001 & - & 69.17 \\
\hline B5 & 3.924 & 3.722 & - & 76.33 \\
\hline $\mathrm{B} 6 \mathrm{a}^{\mathrm{c}}$ & - & 3.845 & - & 61.68 \\
\hline $\mathrm{B} 6 \mathrm{~b}^{\mathrm{c}}$ & - & 3.799 & & \\
\hline $\mathrm{R} 1$ & 5.986 & 5.988 & 92.65 & 88.45 \\
\hline $\mathrm{R} 2$ & 4.371 & 4.375 & - & - \\
\hline R3 & 4.371 & 4.375 & 69.42 & 71.69 \\
\hline $\mathrm{R} 4$ & 4.284 & 4.292 & - & 83.24 \\
\hline R5a & 4.223 & 4.238 & - & 64.94 \\
\hline $\mathrm{R} 5 \mathrm{~b}$ & 4.197 & 4.207 & & \\
\hline $\mathrm{U} 2$ & - & - & 167.20 & 166.56 \\
\hline U4 & - & - & 152.57 & 152.13 \\
\hline U5 & 5.975 & 5.985 & 103.50 & 102.97 \\
\hline U6 & 7.951 & 7.968 & 142.46 & 141.92 \\
\hline
\end{tabular}

$\mathrm{A}=\mathrm{Gal}$ in $\mathbf{3}, \mathrm{A}=\mathrm{Glc}$ in $\mathbf{7 a} ; \mathrm{B}=\mathrm{Gal}$ to $\mathrm{Gal}$ in $\mathbf{3}, \mathrm{B}=\mathrm{Gal}$ to Glc in $\mathbf{7 a}$; R: ribose; U: uracil.

${ }^{a}$ In the case of ${ }^{1} \mathrm{H}$ NMR spectroscopy, A1 means $\mathrm{H}-1$ of residue $\mathrm{A}$. In the case of ${ }^{13} \mathrm{C}$ NMR spectroscopy, $\mathrm{A} 1$ means $\mathrm{C}-1$ of residue $\mathrm{A}$, etc.

${ }^{\mathrm{b}}$ In ppm relative to the signal of external acetone $(\delta 2.225)$.

${ }^{c}$ The assignment of H6a and H6b may have to be interchanged within one residue. 


\section{A: $3 \mathrm{Gal}(\beta 1-4) \mathrm{Gal}(\alpha 1-\mathrm{UDP}$}
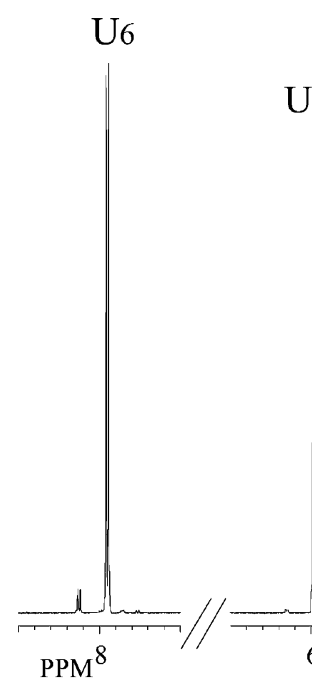

\section{B: 7a Gal $(\alpha 1-3) \mathrm{Glc}(\alpha 1-\mathrm{UDP}$}

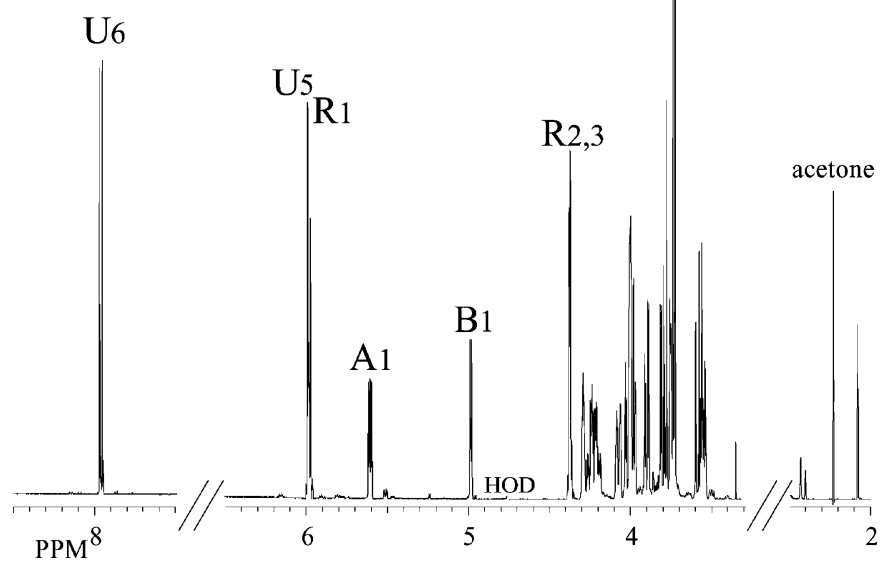

Fig. 3. The 1D $500 \mathrm{MHz}{ }^{1} \mathrm{H}-\mathrm{NMR}$ spectra of the UDP-disaccharides $\mathbf{3}$ and $\mathbf{7 a}$. Samples were analyzed in $\mathrm{D}_{2} \mathrm{O}$ at $300 \mathrm{~K}$. $\mathrm{Gal}(\beta 1-4) \mathrm{Gal}(\alpha 1-\mathrm{UDP}$ (panel A) and $\mathrm{Gal}(\alpha 1-3) \mathrm{Glc}(\alpha 1-\mathrm{UDP}$ (panel $\mathrm{B})$. $\mathrm{A}=\mathrm{Gal}$ in $\mathbf{3}$ and $\mathrm{A}=\mathrm{Glc}$ in $\mathbf{7 a}$; $\mathrm{B}=\mathrm{Gal}$ to Gal in $\mathbf{3}$ and $\mathrm{B}$ $=\mathrm{Gal}$ to Glc in $\mathbf{7 a}$; $\mathrm{R}$ : ribose; $\mathrm{U}$ : uracil.

sign the complete spin systems; a mixing time of $100 \mathrm{~ms}$ allowed the identification of all resonances corresponding to a single residue, whereas a mixing time of $10 \mathrm{~ms}$ made the sequential assignment possible.

To establish the linkage type between residues $\mathrm{A}$ and $\mathrm{B}, 2 \mathrm{D}$ ROESY and HMBC experiments were performed. In the ROESY spectrum (Fig. 4A) the anomeric track of residue B $(\delta 4.600)$ revealed several intraresidual cross-peaks and one inter-residual cross-peak at $\delta 4.262$, which could be assigned as inter-residual contact to $\mathrm{H}-4$ of residue $\mathrm{A}$. In the ${ }^{13} \mathrm{C}-{ }^{1} \mathrm{H}$ HMBC spectrum the visualization of the inter-residual three-bond connectivities over the glycosidic bond yielded unambiguously the determination of the $\mathrm{B}(\beta 1-4) \mathrm{A}$ sequence via two long range 
A3: $\operatorname{Gal}(\beta 1-4) \operatorname{Gal}(\alpha 1-U D P$
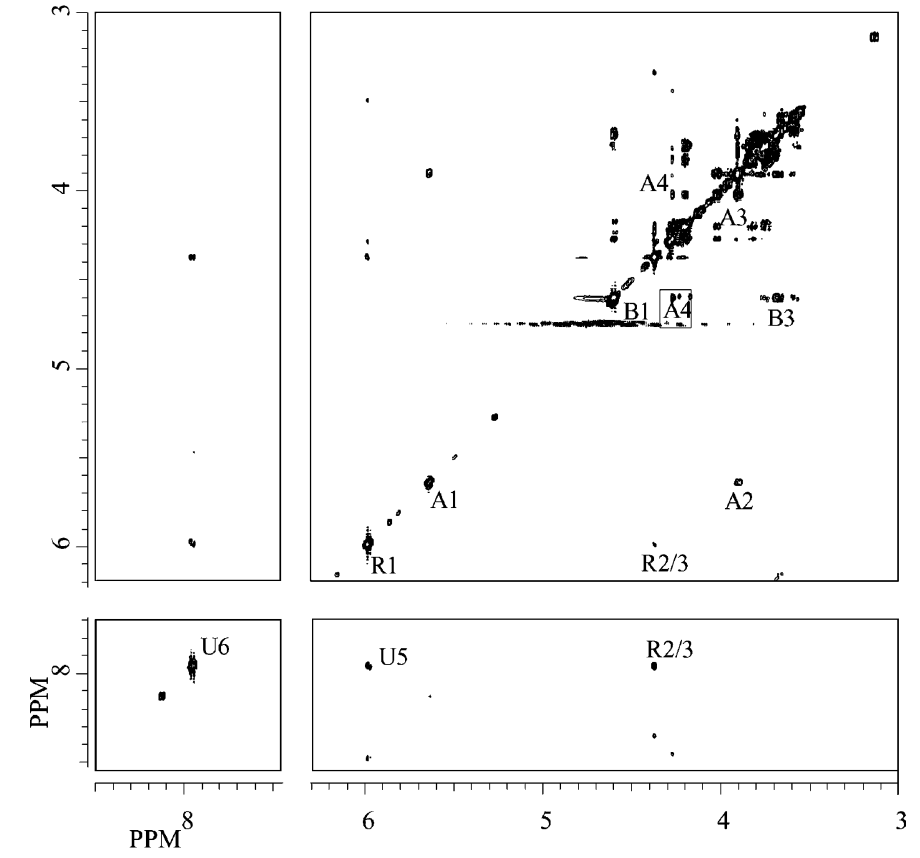

\section{B 7a: $\operatorname{Gal}(\alpha 1-3) \operatorname{Glc}(\alpha 1-U D P$}
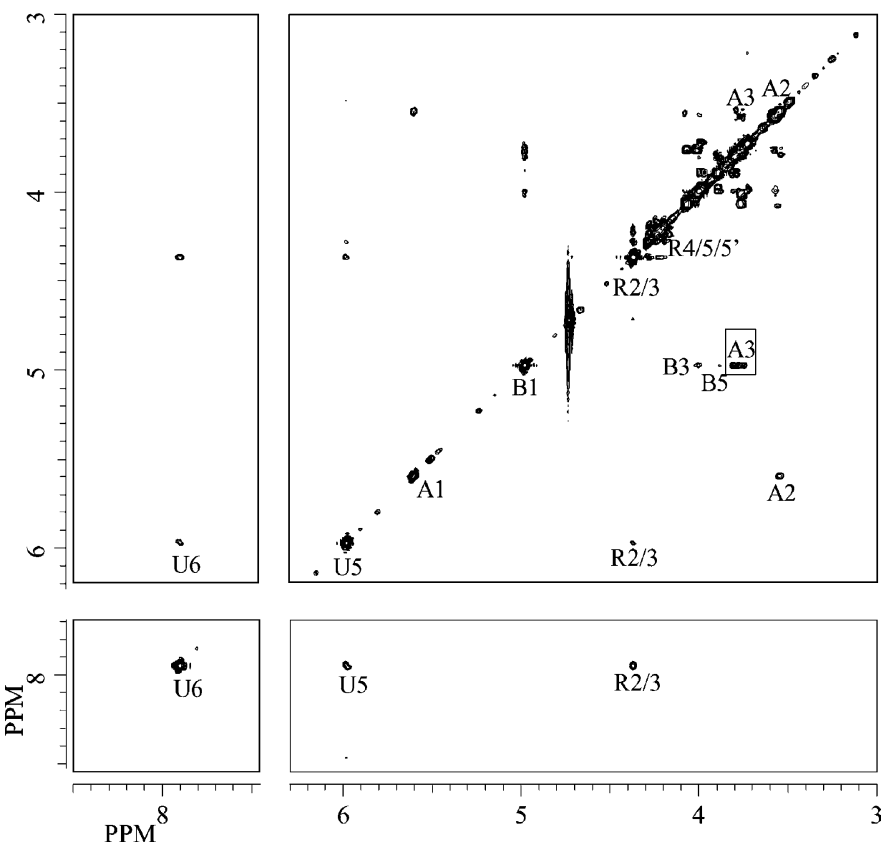

Fig. 4. The 2D 500-MHz 2D ROESY NMR spectra of the UDP-disaccharides 3 and 7a. Samples were analyzed in $\mathrm{D}_{2} \mathrm{O}$ at $300 \mathrm{~K}$ using spin lock times of $250 \mathrm{~ms}$. Gal( $\beta 1-4) \mathrm{Gal}(\alpha 1$-UDP (panel A) and $\mathrm{Gal}(\alpha 1-3) \mathrm{Glc}(\alpha 1$-UDP (panel B). $\mathrm{A}=\mathrm{Gal}$ in $\mathbf{3}$ and $\mathrm{A}=\mathrm{Glc}$ in $\mathbf{7 a}$; $\mathrm{B}$ $=\mathrm{Gal}$ to $\mathrm{Gal}$ in $\mathbf{3}$ and $\mathrm{B}=\mathrm{Gal}$ to Glc in $\mathbf{7 a}$; $\mathrm{R}$ : ribose; $\mathrm{U}$ : uracil. 


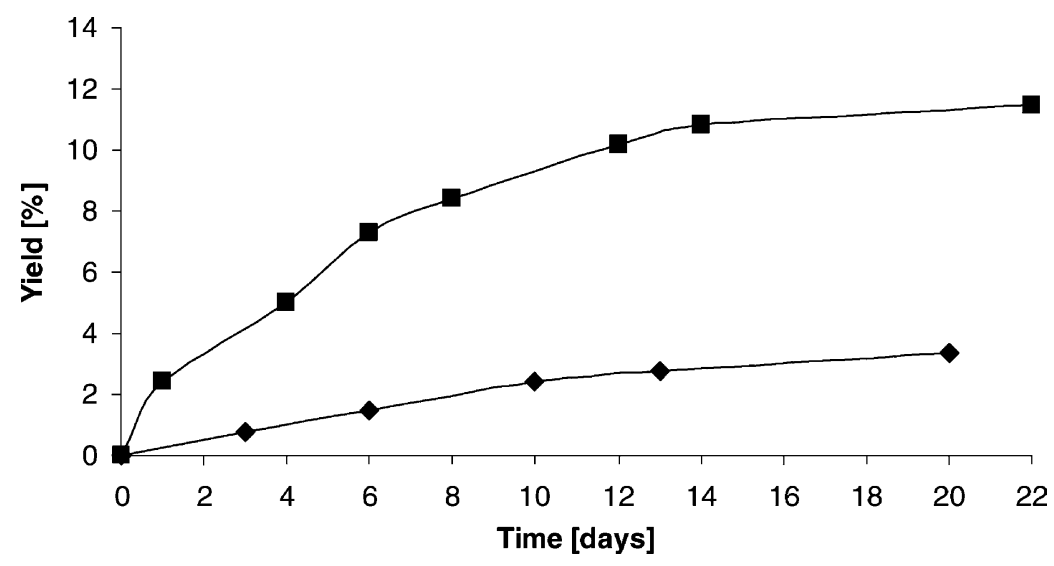

Fig. 5. Effect of the enzyme concentration on the synthesis of the UDP-disaccharide 7a with $\alpha$-galactosidase from Bifidobacterium adolescentis: $5(100 \mathrm{mM})$ and $6(300 \mathrm{mM})$ were incubated at $-5{ }^{\circ} \mathrm{C}$ with $0.5 \mathrm{U} / \mathrm{ml}(\diamond)$ and $6 \mathrm{U} / \mathrm{ml}(\boldsymbol{\square})$ enzyme.

couplings between $\mathrm{B}_{\mathrm{H}-1}$ and $\mathrm{A}_{\mathrm{C}-4}(\delta 4.600,78.74)$ and between $\mathrm{B}_{\mathrm{C}-1}$ and $\mathrm{A}_{\mathrm{H}-4}(\delta 105.22,4.262)$.

In summary, the presented results confirm the regioand stereoselective formation of the $(\beta 1-4)$ glycosidic linkage [10] with 1 as acceptor substrate of the $\beta$-galactosidase of $B$. circulans.

\section{2. $\alpha$-Galactosidase from Bifidobacterium adolescentis}

When using $\alpha$-galactosidase from $B$. adolescentis in the hydrolysis reaction, the enzyme prefers galactosides with an ( $\alpha 1-3)$ linkage over those with an $(\alpha 1-6)$ bond [19]. However, transglycosylation reactions gave exclusively ( $\alpha 1-6)$ linkages with melibiose as donor and acceptor substrate [24]. In the present study, nucleotide sugars, with special interest on UDP-Glc and UDP-Gal, are novel acceptor substrates. In addition, conditions for the synthesis of nucleotide disaccharides were to be determined, using UDP-Glc as model substrate.

\subsubsection{Influence of temperature and donor substrate on the reaction yield}

The transglycosylation reaction of $\alpha$-galactosidase from $B$. adolescentis using UDP-Glc (5) as acceptor substrate was compared at 30 and $-5^{\circ} \mathrm{C}$ (frozen aqueous solution) with either $\operatorname{Gal}(\alpha 1-p \mathrm{NP}$ or $\mathrm{Gal}(\alpha 1-6) \mathrm{Glc}$ (melibiose, 6) as donor substrates.

The formation of an activated disaccharide could only be observed at $-5{ }^{\circ} \mathrm{C}$ with $\mathbf{6}$ as donor substrate.
A nucleotide trisaccharide was not formed. The transglycosylation reaction with $\mathbf{5}$ was very slow at $-5^{\circ} \mathrm{C}$, and the product 7a showed a remarkable stability (Fig. 5). A decrease of the product yield due to hydrolysis could not be observed over 3 weeks of incubation. Higher enzyme concentrations led to higher product yields and did also not induce product hydrolysis. These results confirm the concept described by Hänsler and Jakubke [18] for transfer reactions by hydrolases in frozen solution. A reduced water concentration in the frozen state and an increased concentration of substrates in the small remaining liquid phase (the "freeze-concentration") promote product formation resulting in higher yields.

Most important for our synthesis goal was that the formation of a nucleotide disaccharide by $\alpha$-galactosidase is possible, albeit only in frozen solution.

\subsubsection{Variation of donor substrate concentration}

The influence of different concentrations of melibiose (6) was investigated at $-5^{\circ} \mathrm{C}$. The yields of the nucleotide disaccharide (with respect to the UDP-Glc (5) concentration) were significantly higher when the lower donor concentration $(100 \mathrm{mM})$ was used (Fig. 6). With $500 \mathrm{mM}$ of $\mathbf{6}$, a product yield of only $3.3 \%$ could be detected after 34 days of incubation, whereas at a donor concentration of $100 \mathrm{mM}$ a yield of $6.8 \%$ was obtained. This result was surprising, since it is well known that higher donor substrate concentrations generally favor the product formation in glycosidase-catalyzed transglycosylation reactions 


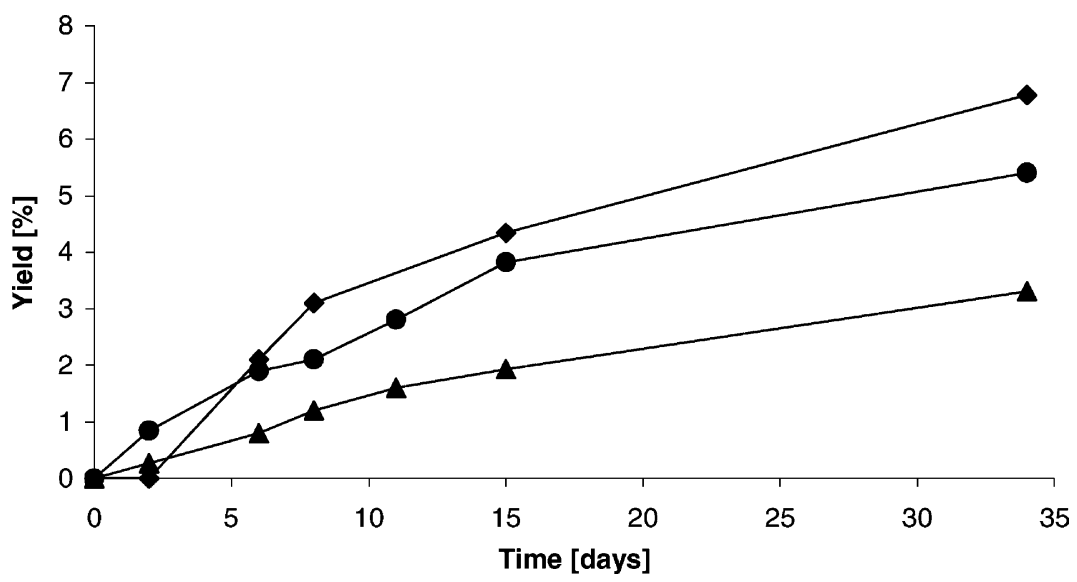

Fig. 6. Effect of different donor concentrations on the synthesis of the UDP-disaccharide 7a with $\alpha$-galactosidase from Bifidobacterium adolescentis: $5(100 \mathrm{mM})$ and $\mathbf{6}(100 \mathrm{mM}$ ), $300 \mathrm{mM}($ ) and $500 \mathrm{mM}$

$(\boldsymbol{\Delta}))$ were incubated with $0.5 \mathrm{U} / \mathrm{ml}$ enzyme at $-5^{\circ} \mathrm{C}$.

[25], which could also be demonstrated for the synthesis of UDP-LacNAc with $\beta$-galactosidase from $B$. circulans using lactose as donor substrate [10].

The decreased product formation at higher donor concentrations may be due to the fact that melibiose is a very good substrate and serves both as donor and acceptor substrate in transglycosylation reactions [24]. Accordingly, the transfer of Gal onto 6 could be favored when the donor:acceptor ratio is higher than $1: 1$. In the present work, we did not follow the formation of oligosaccharide byproducts originating from the donor melibiose, since only nucleotide-activated products were detected in HPLC analysis at $256 \mathrm{~nm}$.

\subsubsection{Synthesis and characterization of Gal $(\alpha 1-3) G l c(\alpha 1-U D P(7 \mathbf{a})$ and synthesis of $\operatorname{Gal}(\alpha 1-3) \operatorname{Gal}(\alpha 1-U D P(7 b)$}

In order to elucidate the type of glycosidic linkage in the nucleotide disaccharide product, synthesis reactions with the nucleotide sugars $\mathbf{5}$ and $\mathbf{1}$ were performed under optimized conditions. The products $\mathbf{7 a}$ and $\mathbf{7 b}$ were synthesized with yields of 5.5 and $5.8 \%$, respectively. The overall yields (referring to the acceptor concentration) of the isolated products were $4.7 \%$ (7.3 mg, $9.4 \mu \mathrm{mol})$ and $3.3 \%(4.1 \mathrm{mg}, 5.3 \mu \mathrm{mol})$ for $7 \mathbf{a}$ and $\mathbf{7 b}$, respectively, with a purity of $100 \%$ according to HPLC. Negative-ion mode MALDI-TOF mass spectrometry of product $7 \mathbf{a}$ revealed a pseudomolecular ion peak at $m / z 729\left([M-\mathrm{H}]^{-}, \mathrm{Hex}_{2}-\mathrm{UDP}\right)$.
The $1 \mathrm{D}{ }^{1} \mathrm{H}$ NMR spectrum of 7a (Fig. 3B) showed five signals downfield of the HOD signal ( $\delta$ 4.751). Three of these signals at $\delta 7.968$ (U6), $\delta 5.985$ (U5) and $\delta 5.988$ (R1) were found at similar positions as described above for 3 . The anomeric doublet at $\delta 5.606$ was assigned to $\mathrm{H}-1$ of the Glc residue A (a configuration, pyranose ring form) linked to the phosphate group. The remaining anomeric signal at $\delta$ 4.985 , downfield of the HOD resonance, reflects H-1 of the $\mathrm{Gal}$ residue $\mathrm{B}$ ( $\alpha$ configuration, pyranose ring form). By means of 2D TOCSY, ROESY and HMBC experiments all resonances observed in the $1 \mathrm{D}{ }^{1} \mathrm{H}$ and ${ }^{13} \mathrm{C}$ spectra could be assigned (Table 1).

In the ROESY spectrum (Fig. 4B) the anomeric track of residue B ( $\delta 4.985)$ revealed an inter-residual cross-peak at $\delta 3.776$, which could be assigned as inter-residual contact to $\mathrm{H}-3$ of residue $\mathrm{A}$. In the ${ }^{13} \mathrm{C}-{ }^{1} \mathrm{H}$ HMBC spectrum (data not shown) the visualization of the inter-residual three-bond connectivities over the glycosidic bond yielded unambiguously the determination of the $\mathrm{B}(\alpha 1-3) \mathrm{A}$ sequence via two long range couplings between $\mathrm{B}_{\mathrm{H}-1}$ and $\mathrm{A}_{\mathrm{C}-3}(\delta$ 4.985, 73.73) and between $\mathrm{B}_{\mathrm{C}-1}$ and $\mathrm{A}_{\mathrm{H}-3}(\delta 98.29,3.776)$.

In summary, $\alpha$-galactosidase from $B$. adolescentis shows an exclusive regio- and stereoselectivity for the formation of the ( $\alpha 1-3)$-glycosidic bond with 5 as acceptor. Changes in regio- and stereoselectivity could not be observed for $\beta$-galactosidase from $B$. circulans when different nucleotide sugars were tested. 
With UDP-Glc, UDP-GlcNAc [10], and UDP-Gal (this report) only ( $\beta 1-4)$ glycosidic linkages were detected in the corresponding nucleotide disaccharide products. Therefore, the assumption is justified that $\mathbf{1}$ as acceptor substrate of $\alpha$-galactosidase from $B$. adolescentis gives $\mathbf{7 b}$ as product. The complete lack of (1-6)-regioisomers in the case of nucleotide sugars as acceptor substrates for both enzymes may be due to the sterical hindrance at the C- 6 of the sugar by the nucleotide moiety. Recently, it could be demonstrated by ab initio calculation that most of the nucleotide sugars comprises conformational families with a folded geometry in water which is stabilized by frequent intramolecular hydrogen bonds between the base and the hexose moiety [26]. The more frequent involvement of the C-6 hydroxyl group in intramolecular hydrogen bonds may explain that the tested glycosidase cannot recognize this position of the hexose and the (1-6)-linkage cannot be formed. This is further supported by our studies with $\beta$-galactosidase from Escherichia coli and Aspergillus oryzae (data not shown), which both were reported to form mainly ( $\beta 1-6)$-glycosidic linkages [27]. Both enzymes did not catalyze the formation of nucleotide disaccharides at 30 and $-5^{\circ} \mathrm{C}$ when UDP-Glc and UDP-GlcNAc, respectively, were used as acceptors. We conclude that the enzymatic transfer of a sugar onto the C-6 hydroxyl group of the hexose moiety of a nucleotide sugar might not be possible because of sterical hindrance.

\section{Conclusions}

We have established the access to three different nucleotide disaccharides by glycosidase-catalyzed transglycosylation reactions in frozen aqueous solution. These compounds will facilitate investigations on the biochemical role of these glycoconjugates. Our future work will concentrate on the use of these novel glycoconjugates as building-block substrates of Leloir glycosyltransferases as well as investigations on their biochemical function as inhibitors of glycosyltransferases and nucleotide sugar transporters.

\section{Acknowledgements}

L. Elling gratefully acknowledges financial support by the Deutsche Forschungsgemeinschaft (DFG, EL
135/4-1 and EL 135/4-3) and the Fonds der Chemischen Industrie.

\section{References}

[1] A. Kobata, Biochem. Biophys. Res. Commun. 7 (1962) 346.

[2] A. Kobata, J. Biochem. 53 (1963) 167.

[3] A. Kobata, J. Biochem. 59 (1966) 63.

[4] A. Kobata, S. Ziro, Biochim. Biophys. Acta 107 (1965) 405.

[5] G.W. Jourdian, F. Shimizu, S. Roseman, Fed. Proc. 20 (1961) 161.

[6] G.W. Jourdian, J.J. Distler, J. Biol. Chem. 248 (1973) 6781.

[7] R.E. Denamur, P.J.-B. Gaye, Eur. J. Biochem. 19 (1971) 23.

[8] Y. Nakanishi, S. Shimizu, N. Takahashi, M. Sugiyama, S. Suzuki, J. Biol. Chem. 242 (1967) 967.

[9] S. Suzuki, J. Biol. Chem. 237 (1962) 1393.

[10] A. Zervosen, V. Nieder, R. Gutiérrez Gallego, J.P. Kamerling, J.F.G. Vliegenthart, L. Elling, Biol. Chem. 382 (2001) 299.

[11] E. Hartmann, H. König, Naturwissenschaften 77 (1990) 472.

[12] E. Hartmann, H. König, Biol. Chem. Hoppe Seyler 372 (1991) 971.

[13] E. Hartmann, P. Messner, G. Allmeier, H. König, J. Bacteriol. 175 (1993) 4515.

[14] K.M. Koeller, C.-H. Wong, Chem. Rev. 100 (2000) 4465.

[15] L. Elling, in: T. Scheper (Ed.), Advances in Biochemical Engineering/Biotechnology, vol. 58, Springer, Berlin, 1997, p. 89.

[16] L. Elling, A. Zervosen, R. Gutiérrez Gallego, V. Nieder, M. Malissard, E.G. Berger, J.F.G. Vliegenthart, J.P. Kamerling, Glycoconjugate J. 16 (1999) 327.

[17] C.-H. Wong, Y. Ichikawa, T. Krach, C. Gautheron-Le Narvor, D.P. Dumas, G.C. Look, J. Am. Chem. Soc. 113 (1991) 8137.

[18] M. Hänsler, H.-D. Jakubke, Amino Acids 11 (1996) 379.

[19] S. Leder, W. Hartmeier, S.P. Marx, Curr. Microbiol. 38 (1999) 101.

[20] T. Bülter, L. Elling, J. Mol. Catal. B: Enzymatic 8 (2000) 281.

[21] G.R. Guile, P.M. Rudd, D.R. Wing, S.B. Prime, R.A. Dwek, Anal. Biochem. 240 (1996) 210-226.

[22] R. Köplin, J.-R. Brisson, C. Whitfield, J. Biol. Chem. 272 (1997) 4121

[23] J.H. Yoon, K. Ajisaka, Carbohydrate Res. 292 (1996) 153.

[24] K.M.J. Van Laere, R. Hartemink, G. Beldman, S. Pitson, C. Dijkema, H.A. Schols, A.G.J. Voragen, Appl. Microbiol. Biotechnol. 52 (1999) 681.

[25] K.G.I. Nilsson, in: S.H. Khan, R.A. O'Neill (Eds.), Modern Methods in Carbohydrate Synthesis, vol. 1, Harwood, Amsterdam, 1996, p. 518.

[26] P. Petrová, J. Koca, A. Imberty, J. Am. Chem. Soc. 121 (1999) 5535.

[27] S. Reuter, A.R. Nygaard, W. Zimmermann, Enzyme Microb. Technol. 25 (1999) 50. 